\title{
Histoire sainte
}

\author{
Carole David
}

An anorexic Catholic girl, fascinated with images of religious suffering, coaxes her dealer into an attempt to walk on water.

La fille s'appelle Corinne Gilbert. Elle souhaite être sainte depuis qu'elle est au primaire. Elle aime les images du Christ en croix et son coeur, n'en parlons pas. Sa collection d'images pieuses impressionne les religieuses à un tel point qu'elles ont organisé une exposition pour elle seule. En méthode, Soeur Marie-Évariste désigne lors d'un cours de latin les jeunes filles susceptibles de revêtir la robe de novice, Corinne Gilbert est nommée une des premières candidates.

Elle se mutile déjà depuis quelque temps.

Poignets, pieds, cheveux, cils parfois.

Cette dimension de la souffrance la fascine. Elle refuse l'invitation qui lui a été faite la jugeant trop peu élevée pour ses aspirations. Dans l'ombre, elle calque son destin sur les vies de celles qui l'inspirent notamment, la petite Thérèse, Catherine de Sienne et Kateri Tékakwitha dont elle a visité le village l'été dernier.

Ses parents ignorent son aversion pour la nourriture. Plus d'une fois une âme charitable l'a ramassée dans l'autobus ou le métro. Quand ces moments privilégiés arrivent, elle y est préparée depuis quelques minutes déjà. Une chaleur diffuse monte en elle et atteint les extrémités de son corps. L'effet, de courte durée, est semblable à celui que procure un hit d'héroïne. Quand la sensation s'amenuise, ses membres contractés se relâchent et elle s'écroule. Elle déteste les changements qui s'effectuent sur son corps: ces rondeurs, son visage atteint par l'acné, ses cheveux lisses et soyeux devenus rêches.

Elle jette la nourriture enfouie dans les poches dans les poubelles qu'elle trouve sur le chemin de l'école. « Je suis une fille maigre et j'ai de beaux os ", se répète-t-elle en marchant tête droite vers l'absolu qu'elle s'est fixé. Dieu lui a parlé, mais elle garde le secret. Le miracle se produit un soir où elle meurt d'ennui en compagnie de sa jeune soeur. Après plusieurs appels logés à gauche et à droite chez différents amis, elles rejoignent Fred, un 
dealer.

« Mon stock est OK les filles, passez à la maison. »

$* * *$

Madame Morgenstein, la mère de Fred, repasse, les yeux baissés. Les vêtements sont éparpillés dans la maison: sur les divans, les chaises de la cuisine et les lits. Son fils fait des aller-retour du salon au sous-sol où il puise dans le congélateur familial. Sa marchandise est enfouie sous les petits pois, les carottes et du boeuf dépecé en quartiers. Souvent, ses clients assidus le suivent au Jardin Botanique où il enterre une autre partie de la drogue dans une section abandonnée par la direction, mais fréquenté par les étudiants du collège et les fumeurs de pot. Fred suggère à Corinne et à son amie de dropper tout de suite les deux caps de mescaline.

"Préparez-vous, l'effet est rapide. Je veux vous voir tripper les filles; maintenant vous allez monter très haut. »

Corinne lui tend un billet de dix dollars emprunté dans le portefeuille de sa mère; elle se lève et se rassoit aussitôt. La mère de Fred vaporise un empois sur les chemises blanches de son mari.

"Hey m'man, ça sent fort ton affaire. C'est pire que de la dope, ça. "

Le fer à repasser va et vient dans tous les sens comme si madame Morgenstein en avait perdu le contrôle. La vapeur se répand dans la cuisine et de petits nuages se forment au-dessus de leurs têtes, Corinne Gilbert a sa première apparition. Le Christ lui sourit et tend ses bras vers elle en murmurant des mots latin qu'elle n'a pas appris.

« Pis, Corinne qu'est-ce que t'en penses? T'as l'air pas mal partie. »

«Maudit nono, tu m'as fait perdre mon idée. »

L'image est disparue aussitôt que Fred a commencé à rire et à parler. Malgré ses efforts répétés, Corinne n'a plus cette image claire et définie du Christ lui souriant et lui demandant de le rejoindre. Le repassage de madame Morgenstein n'est pas terminé; d'autres nuages, d'autres bulles ont la chance de se former et d'accueillir à nouveau cette image.

"Occupez-vous pas de ma mère, elle comprend même pas le français. On peut vraiment dire ce qu'on veut. "

La mère de Fred le gronde dans une langue que Corinne ne connaît pas.

" Parle-t-elle la langue du Christ? C'est possible, se dit-elle, Jésus était juif après tout. Les juifs sont-ils plus heureux que les catholiques? »

Corinne est montée au ciel, elle en est persuadée. Son corps s'est détaché d'elle, elle ne le sent plus.

«Les filles, un tour d'auto, ça vous tente? » 


\section{$24 \cdot$ Tessera}

\section{$* * *$}

Le fleuve, à cet endroit, est menaçant depuis que le pont-tunnel a été construit; ses abords ont été modifiés. Fred leur explique l'historique de la construction avec moult précisions.

«Toi, Fred, serais-tu capable de marcher sur l'eau? » lui demande Corinne.

«Avec ce que j'ai pris, j'y arriverais sûrement. »

« Ne fais pas de niaiseries » lui crie la soeur de Corinne.

"Juste essayer un tour les filles, regardez-moi aller! »

Fred avance dans l'eau avec ses bottes de motard.

"Tu vois bien que t'es pas Jésus, tu cales au lieu de monter. Tu crois même pas en Dieu, lui dit Corinne. T'as l'air du diable en personne. »

Malgré les cris et les appels des deux jeunes filles, le dealer s'enfonce jusqu'à ce qu'il ne reste plus que sa tête hors de l'eau. Il a juste le temps de se retourner et en quelques secondes à peine, il disparaît. Corinne reste sur la berge pendant que sa soeur se précipite vers la maison la plus proche espérant y trouver de l'aide.

Les secouristes arrivent, l'ambulance et quelques curieux se massent sur les abords du fleuve. Les policiers amènent les deux filles sur la banquette arrière et les interrogent sur l'incident. Les plongeurs ratissent déjà le périmètre de la présumée noyade.

Corinne Gilbert s'agenouille et prie, elle demande de sauver Fred, de lui redonner la vie là au fond de l'eau. Seule au milieu des spectateurs hébétés, elle est envahie par cette chaleur familière.

\section{$* * *$}

De peur d'être aperçu par les policiers qui ratissent les alentours de la berge, Fred enfile ses pantalons de rechange et sa chemise hawaïenne. Le temps ne lui appartient plus, à quelques minutes de marche du domicile familial, il n'y a pas de chances à prendre. Le parcours est bondé de curieux, de flics.

Madame Morgenstein n'a pas bougé, le fer à repasser court dans tous les sens, les nuages se sont accumulés.

"Tiens voilà Houdini de retour! Une bonne fois, tu vas te faire prendre. "

Corinne Gilbert ne prie plus; les policiers lui offrent de les raccompagner, elle et sa soeur, à la maison. 